\title{
RANCANG BANGUN DAN MONITORING IP CAMERA B ERBASIS OPEN-WRT PADA KANTOR PDAM TIRTA BERKAH PANDEGLANG
}

\author{
Saleh Dwiyatno ${ }^{1}$, Muhamd Rosi Sadi ${ }^{2}$, M. Natsir ${ }^{3}$ \\ Universitas Serang Raya \\ Jl. Jalan Raya Serang Cilegon Drangong Taktakan Kota Serang Banten \\ Email : salehdwiyatno@gmail.com ${ }^{1}$, ociw46@gmail.com ${ }^{2}$, \\ muhamadnatsir@gmail.com ${ }^{3}$
}

\begin{abstract}
The development of CCTV technology makes it easier for a user in monitoring and monitoring a room or environment. But the lack of CCTV is a price that is still not reached by all levels of society. Because of this, it is necessary to build a new system that has the same features with CCTV tools in circulation but with a more affordable price.The new system is built by utilizing the openWRT operating system. The openWRT operating system will be installed on a wireless router with some additional tools to support its functionality such as speakers, soundcards, loudspeakers, webcam and flashdrive. The resulting system will have the ability to detect motion, the system is also capable of storing images, video and send snapshots via email when detected suspicious motion. In addition, this system also has some other features such as alarm alerts, motion detection scheduling so that its usage can be set as needed and easy access via internet so that can be accessed anywhere as long as connected to the internet
\end{abstract}

Keywords: CCTV, OpenWRT, Wireless Router

\section{PENDAHULUAN}

Seiring dengan era globalisasi dan peningkatan pertumbuhan ekonomi, mengakibatkan manusia untuk bertindak cenderung konsumtif. Bahkan sifat konsumtif ini tidak memandang apakah harta benda yang dimiliki itu hak miliknya atau milik orang lain sehingga mengakibatkan terjadinya kasus kriminal, seperti pencurian.

Di lain sisi, kemajuan teknologi melahirkan sistem monitoring dengan menggunakan perangkat Closed Circuit Television (CCTV). Penggunaan perangkat ini dapat mempermudah dalam memantau situasi dan kondisi suatu ruangan, sehingga dapat mencegah terjadinya suatu tindakan kejahatan.Namun demikian, harga CCTV yang mahal membuat perangkat ini belum bisa dijangkau semua orang dan kebanyakan CCTV hanya dapat diakses secara local saja pada daerah lingkup tertentu. 
Dengan dua latar belakang tersebut munculah ide penulis untuk membangun sebuah sistem yang mampu dijadikan sebagai sarana monitoring ruangan yang mudah diakses, praktis dan hemat. Sistem monitoring rumah ini menggunakan perangkat nirkabel yang akan dimodifikasi dan disesuaikan dengan kebutuhan pengguna. Diharapkan dengan teknologi nirkabel ini sistem akan menjadi lebih praktis dan mudah untuk diakses dari mana saja menggunakan koneksi internet.

Berdasarkan uraian pendahuluan diatas, maka permasalahan yang terjadi dapat disimpulkan sebagai berikut:

1. Bagaimana merancang sistem keamanan kamera pengawas yang dapat mendeteksi gerakan mencurigakan?

2. Bagaimana memberikan informasi kepada pengguna secara realtime ketika terdeteksi gerakan mencurigakan pada jam-jam tertentu ?

\section{PEMECAHAN MASALAH}

\section{Manajemen Jaringan}

Sistem monitoring ruangan yang akan dibangun ini merupakan sebuah alternatif baru didalam bidang keamanan. Sistem ini dibangun secara embedded pada sebuah router dengan sistem operasi OpenWRT.

Sistem yang akan dibangun ini memiliki kemudahan dalam mengakses dan mengontrol sistem. Antar muka yang dibangun berbasis webakan memudahkan admin karena dapat diakses mengunakan komputer, laptop, tablet maupun handphone. Adanya internet akan memudahkan admin dalam mengontrol keadaan ruangannya. Sehingga ruangan/kantor yang telah terpasang sistem ini akan tetap aman ketika sudah sepi dari aktifitas para pegawai karena memiliki fitur remote jarak jauh.

\section{Topologi Jaringan CCTV}

Topologi jaringan CCTV pada kantor PDAM Tirta Berkah Pandeglang yang menggunakan sistem CCTV berbasis openwrt yang memiliki sistem deteksi gerakan dan notifikasi melalui email. 


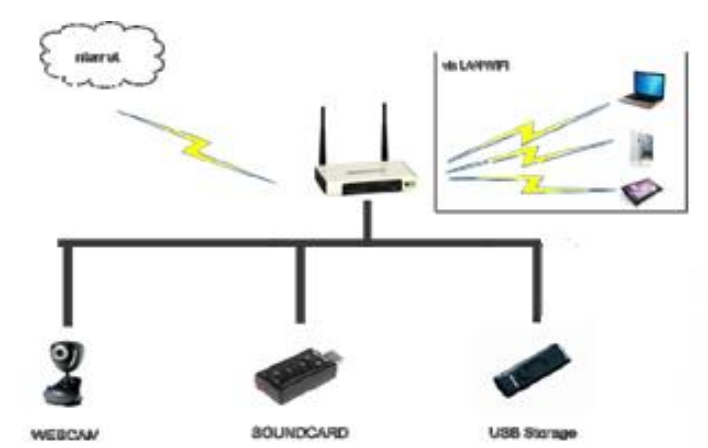

Sumber: Dokumen Pribadi

Gambar 1 Topologi Jaringan

\section{Skema Jaringan CCTV}

Skema yang diterapkan yaitu sebagai berikut:

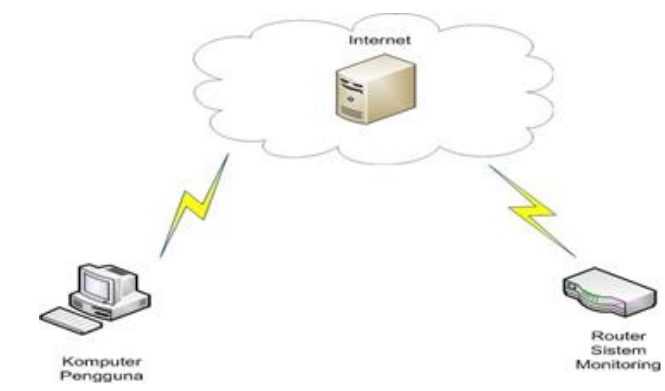

Sumber: Dokumen Pribadi

Gambar 2 Skema Jaringan

\section{Sistem Keamanan}

Sistem keamanan yang ada pada kantor PDAM Tirta Berkah Pandeglang yaitu menggunakan CCTV analog yang hanya dapat di monitoring secara lokal. Untuk meningkatkan sistem keamanan pada kantor PDAM Tirta Berkah Pandeglang maka digunakan sistem tambahan yaitu sistem pendeteksi gerakan, notifikasi melalui email dan dapat di akses secara online.

\section{Rancangan Sistem}

Perancangan sistem yang akan digunakan untuk merancang suatu sistem monitoring suatu ruangan yang dapat mendeteksi gerakan dengan mengatur penjadwalan deteksinya dan memberikan notifikasi melalui email, yang sebelumnya membutuhkan sebuah firmware atau software yang diperlukan untuk membangun sistem tersebut yang nantinya akan bekerja sama untuk dapat menjalankan sistem monitoring berbasis openwrt maka dibutuhkan software sebagai berikut: 
1. Firmware openwrt pulpstone-lede-squashhfs-factory.bin http://pulpstone.pw/id/firmware-id

2. Bitvise ssh client http://bitvise.com/ssh-client-download

\section{Instalasi Firmware}

Pulpstone.pw menyedikan paket instalasi yang sesuai dengan device dan versi yang kita miliki yang dapat kita download di dari link: http://pulpstone.pw/basicar71xx/. Lakukan langkah berikut untuk meng-upgrade firmware bawaan router:

Langkah pertama yang harus dilakukan yaitu Login web config Tp-Link kemudian ke system tool > upgrade firmware, lalu browse file firmware openwrt klik upgrade.

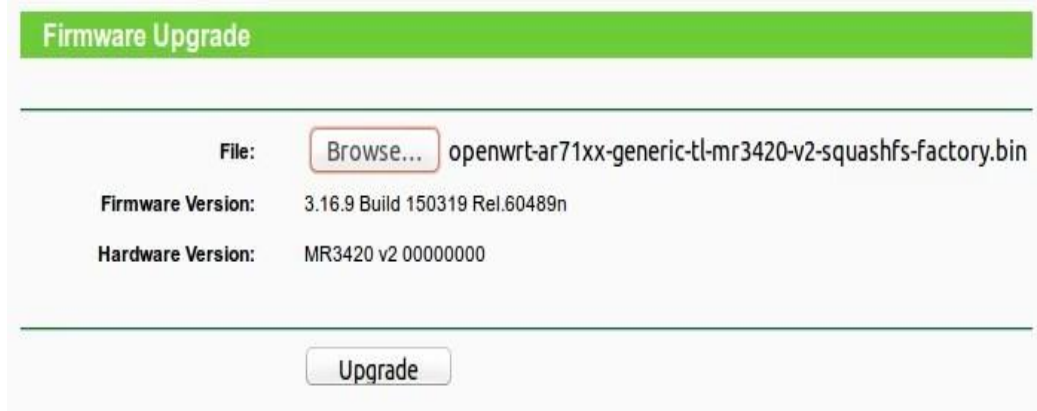

Sumber: Dokumen Pribadi

Gambar 3 Upgrade Firmware

Setelah itu tunggu proses upgrade selesai dan jika berhasil routerakan melakukan restartotomatis hingga muncul gambar seperti pada gambar 4.

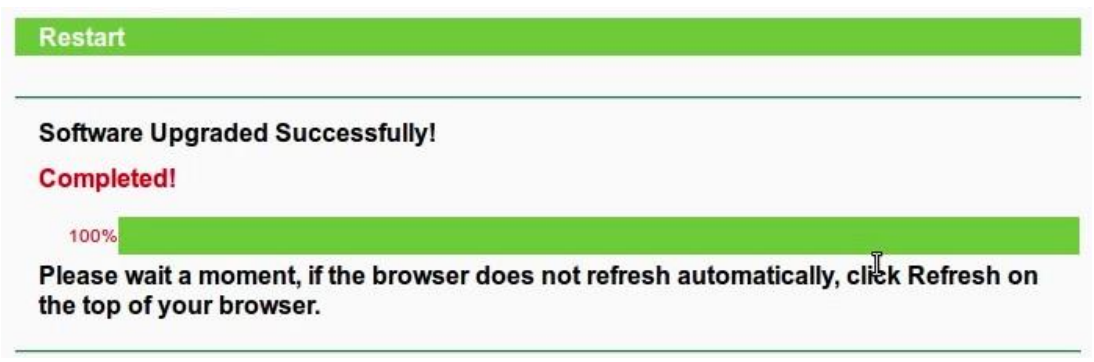

Sumber: Dokumen Pribadi

Gambar 4 Proses Upgrade

Disconnect dan reconnect jaringan kabel untuk mendapatkan IP Address baru, IP Address default OpenWRT 192.168.1.1 dengan username root passwordroot. Buka 
browser dan ketikan ip default openwrt maka akan muncul tampilan seperti pada gambar 5.

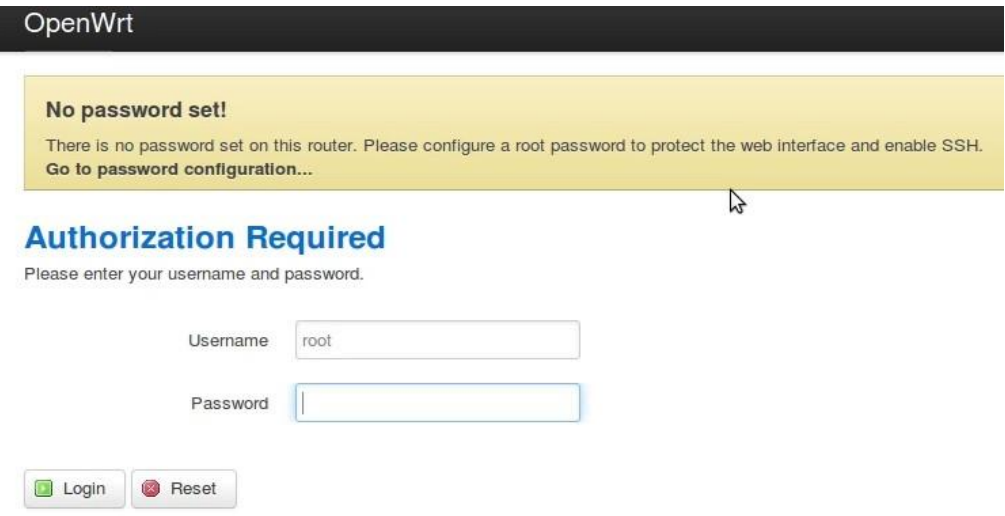

Sumber: Dokumen Pribadi

Gambar 5 Tampilan login openwrt

Login dengan mengetikan username root dan password root maka akan masuk keinterface openwrt seperti gambar 6.

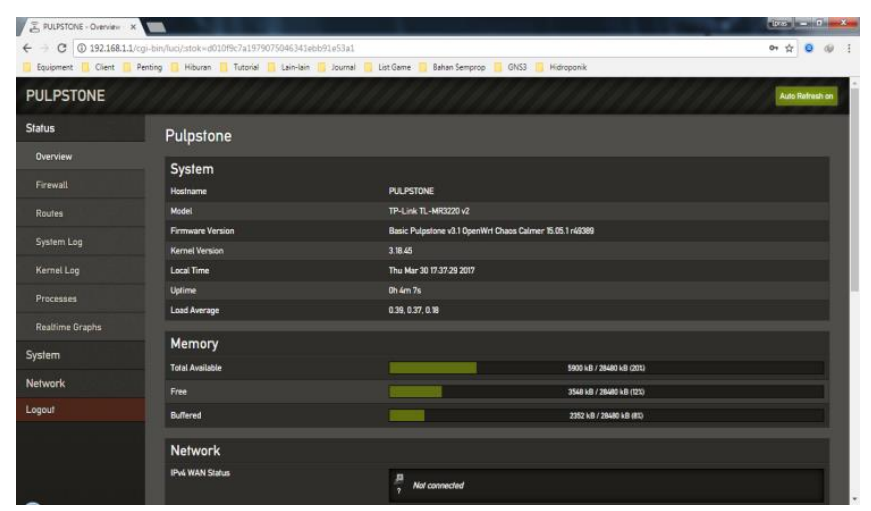

Sumber: Dokumen Pribadi

Gambar 6 Tampilan web interface openwrt

Jika sudah masuk kedalam interface openwrtpulpstone seperti gambar di atas maka upgrade firmware openwrt pada router selesai dan sukses.

\section{Installbitvise ssh client}

Untuk menginstal aplikasi bitvise ssh clinet download terlebih dahulu aplikasi pada link: http://bitvise.com/ssh-client-download. Jika sudah download maka hal pertama yang harus kita lakukan yaitu:

1. Double klik pada setup aplikasi yang sudah kita download. 
2. Centang semua pilihan seperti I Agree to accept dan yg lain seperti gambar 7

3. Klik install dan tunggu hingga selesai.

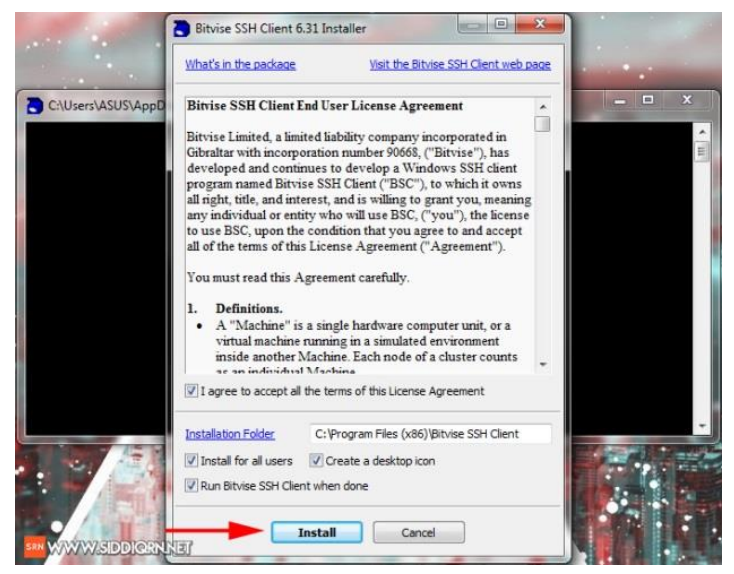

Sumber: Dokumen Pribadi

\section{Gambar 7 Install bitvise}

Setelah proses install selesai maka tampilan awal dari bitvise ssh client seperti pada gambar 8.

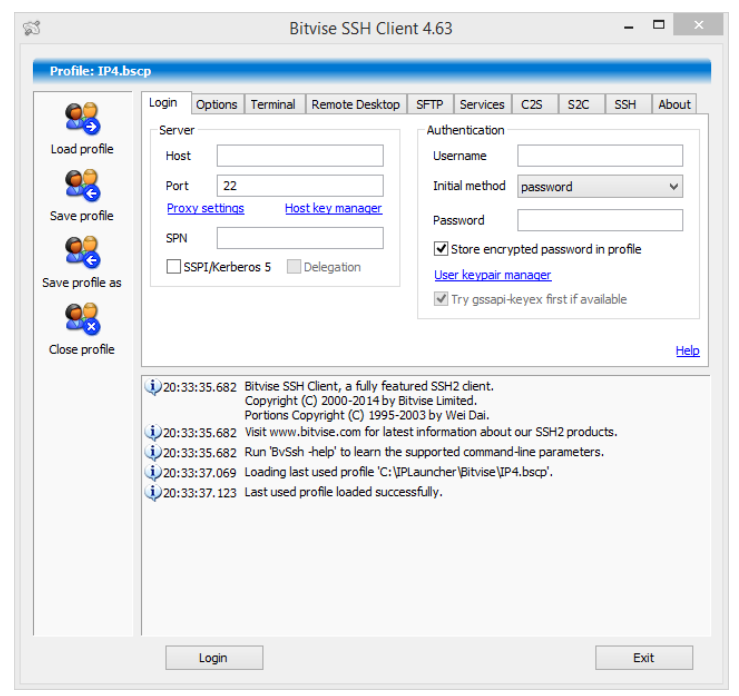

Sumber: Dokumen Pribadi

Gambar 8 Tampilan awal bitvise

\section{Exroot}

Exroot merupakan cara untuk menambahkan internal storage pada router yang sudah terinstal OpenWrt dengan memanfaatkan port usb yang ada, dalam penelitian ini penulis menggunakanFlash Disk. Sebelum membuat partisi pada flash disk yang kan digunakan, satu partisi sebagai swap dan satu partisi lagi yang akan kita gunakan untuk internal storage dengan file sistem ext4. Pada penelitian 
ini penulis menggunakan MiniTool Partition Wizard untuk membuat partisinya untuk men-download aplikasi ini tersedia pada link berikut: https://www.partitionwizard.com/download.html.

Install mini tool partition yang sudah didownload lalu bukan aplikasi tersebut dan mulai untuk membuat partisi seperti gambar berikut:

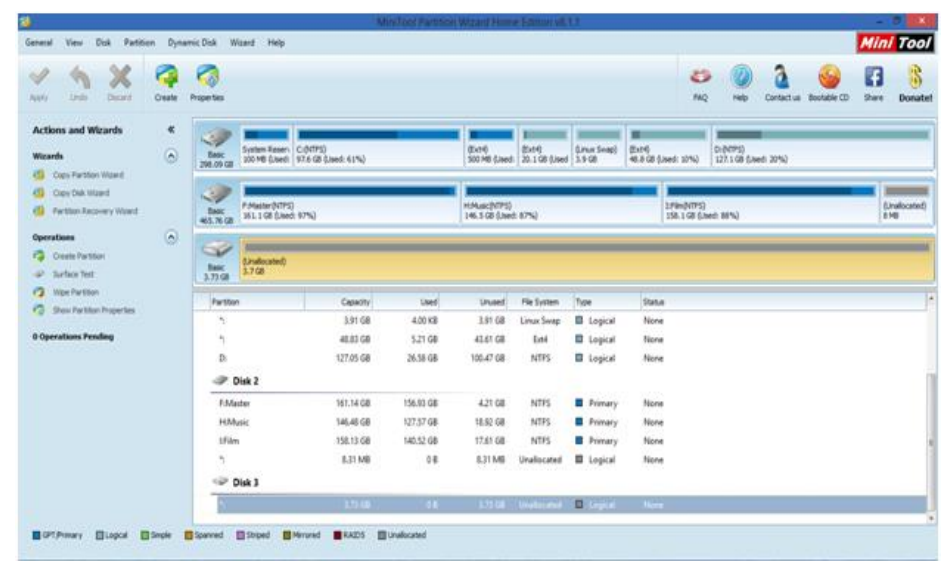

Sumber:Dokumen Pribadi

Gambar 9 Tampilan awal mini tool partition

Delete terlebih dahulu partisi yang sudah ada dalam flash disk, kali ini penulis menggunakan flash disk 4GB. Lalu buat 2 partisi yaitu swap dan ext4 pada aplikasi mini tool partition.

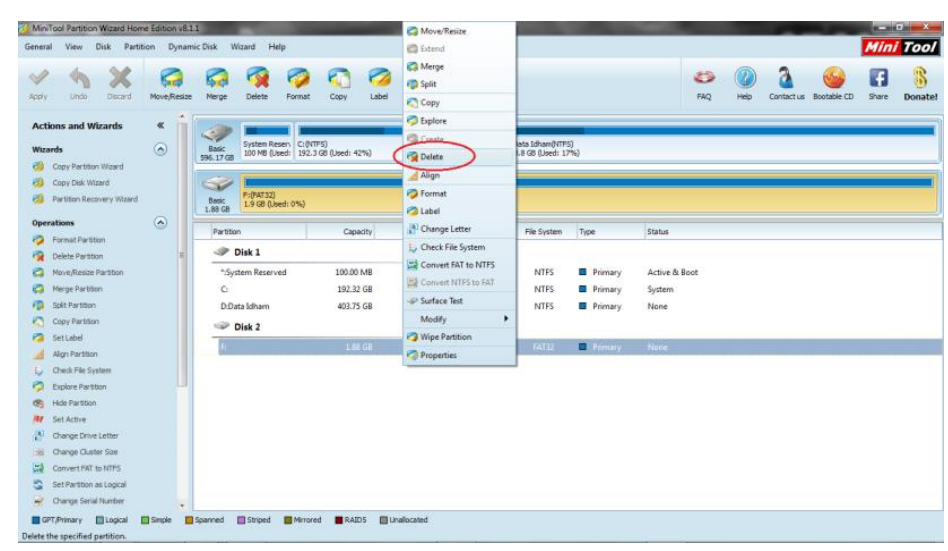

Sumber: Dokumen Pribadi

Gambar 10 Delete Flashdisk

Jika sudah di delete lalu klik kanan kembali pada flashdik dan pilih create seperti gambar dibawah ini: 


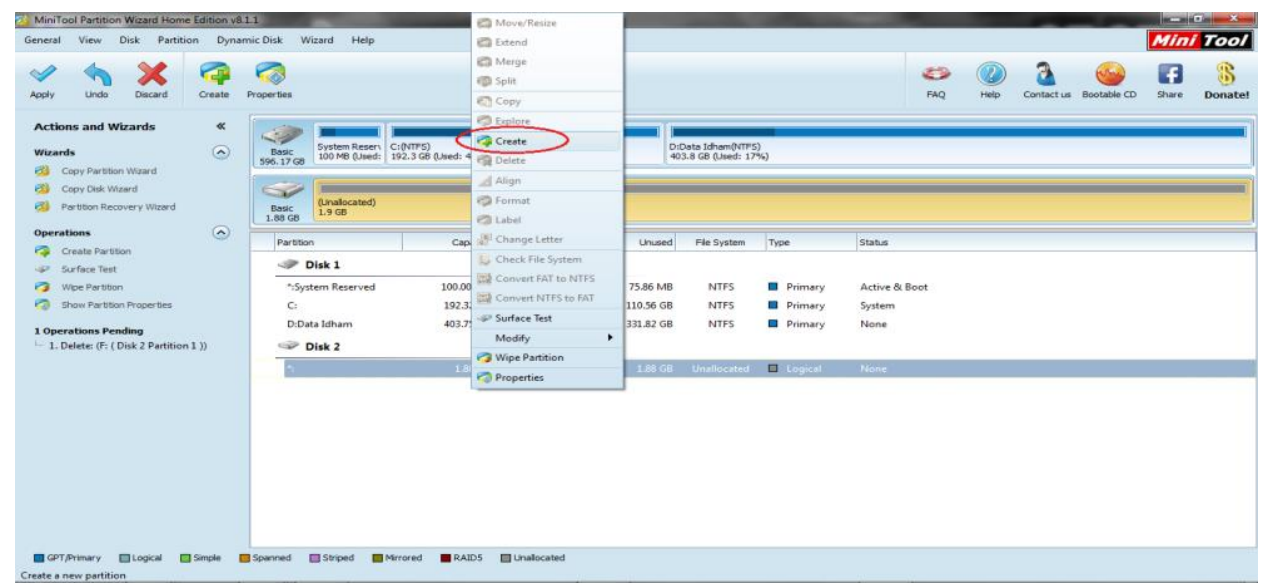

Sumber: Dokumen Pribadi

Gambar 11 Create Partisi

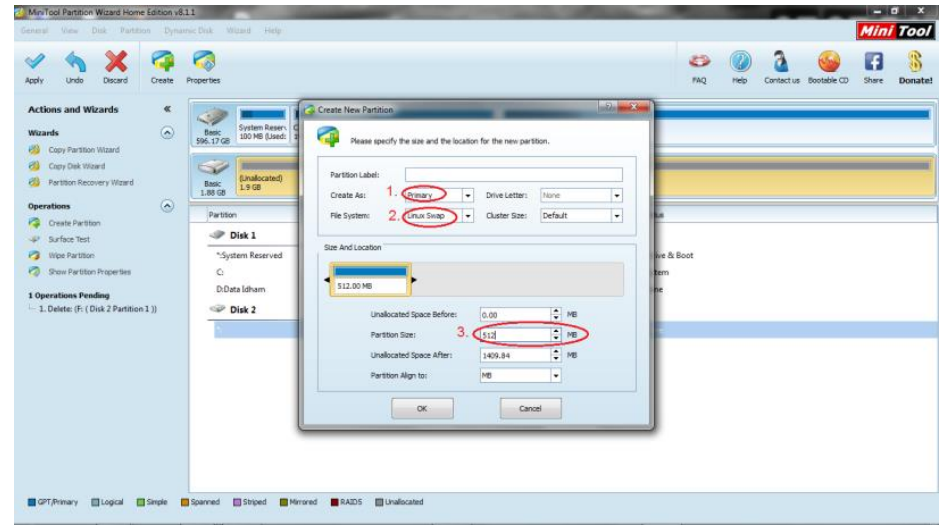

Sumber: Dokumen Pribadi

Gambar 12 Partisi SWAP

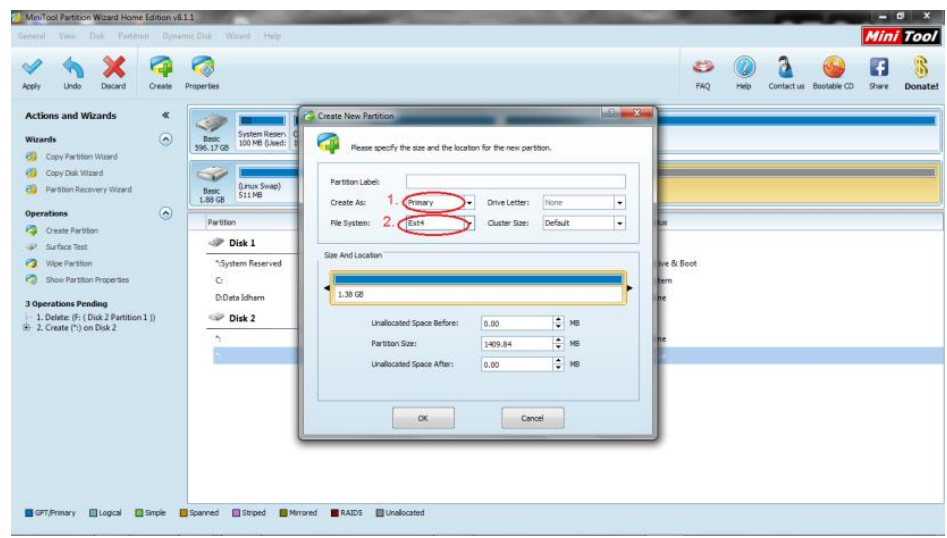

Sumber: Dokumen Pribadi

Gambar 13 Partisi Ext4

Setelah itu Apply dan tungggu hingga partisi selesai dibuat. 


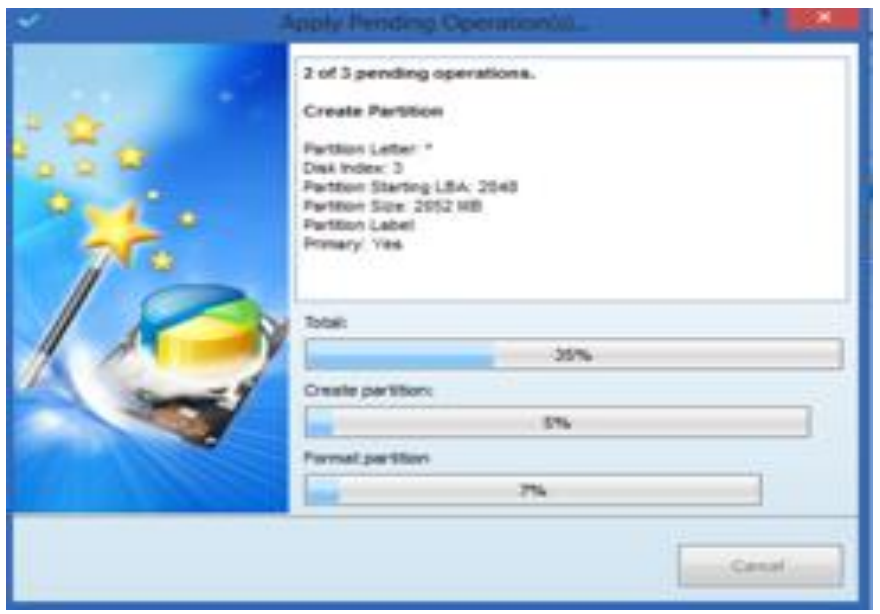

Sumber: Dokumen Pribadi

Gambar 14 Proses pembuatan partisi

\section{Install Dan Konfigurasi Motion}

Untuk menginstal aplikasi motion pada router openwrt maka hal pertama yang harus dilakukan yaitu:Buka aplikasi bitvise ssh client masukan ip router openwrt pada kolom host 192.168.2.1 dan pada kolom username ketikan root lalu pada kolom password ketikan root juga lalu klik login.

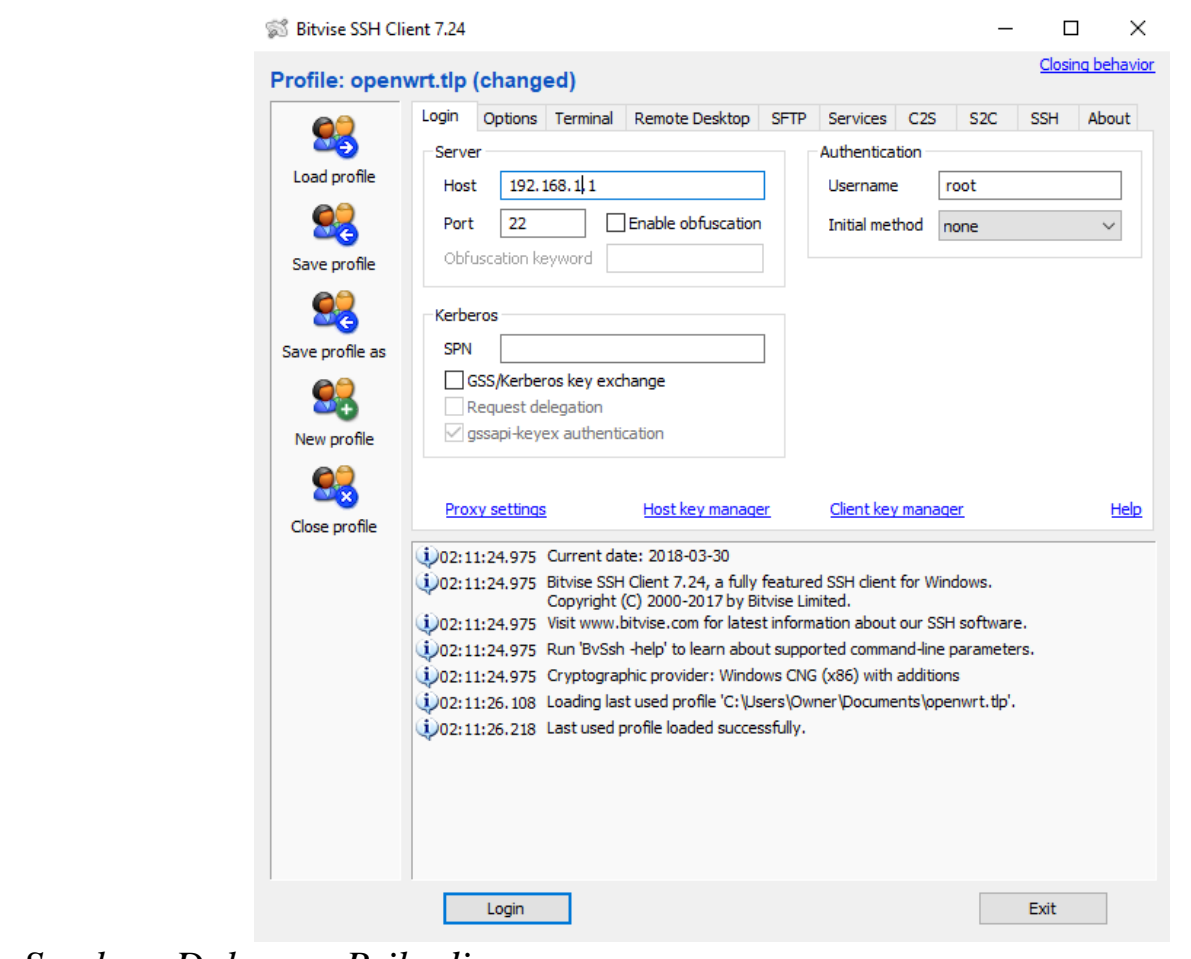

Sumber: Dokumen Pribadi

Gambar 20 Tampilan awal login bitvise 
Untuk mempermudah saat login sebaiknya kita buat profile pada aplikasi bitvise ssh client. Setelah itu maka akan muncul tampilan openwrt via terminal bitevise ssh client seperti berikut:

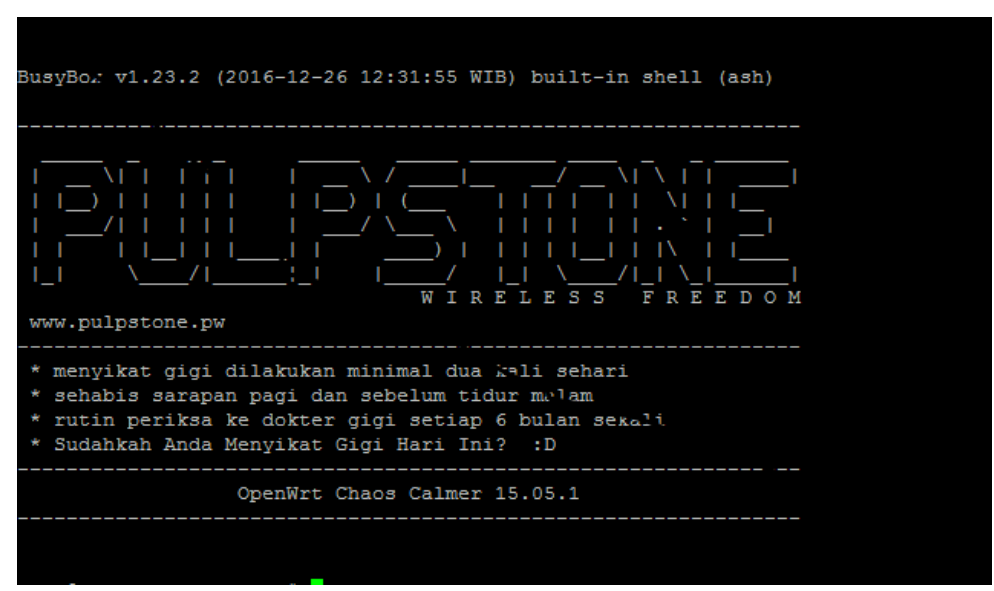

Sumber: Dokumen Pribadi

Gambar 21 Tampilan openwrt melalui terminal bitvise

Jika sudah masuk terminal bitvise ssh instal dan konfigurasi motion ketikan perintah seperti berikut:

\# opkg install kmod-usb-core kmod-usb2 kmod-video-core

Tunggu hingga prosesnya sampai selesai.Perintah ini digunakan sebagai perintah untuk membaca port usb pada webcam, Jika sudah lanjut perintah selanjutnya.

\#opkg install libpthread zlib libjpeg libfaad2

\# opkg install kmod-video-uvc

Ini adalah perintah untuk menginstal driver webcam yang kita gunakan. Setelah selesai coba kita cek direktori/dev terlebih dahulu apakah webcam kita sudah terbaca oleh sistem atau tidak dengan cara mengetikan perintah:

\# ls - al /dev/videoO

Jika sudah terbaca maka akan muncul tulisan seperti ini:

crw-r--r-- 1 root root 81, o Sep 8 23:02/dev/video0

Ini tandanya webcam kita sudah terbaca pada port usb, lanjut menginstal motion dengan perintah:

\# opkg install motion.

edit beberapa parameter di /etc/motion.conf

stream_localhost on diganti off

locate_motion_mode off digantion 
untuk menjalankan motion ketikan perintah pada terminal dengan perintah: \#motion -c letc/motion.conf.

Berikut codeing perintah ketika aplikasi motion telah berjalan:

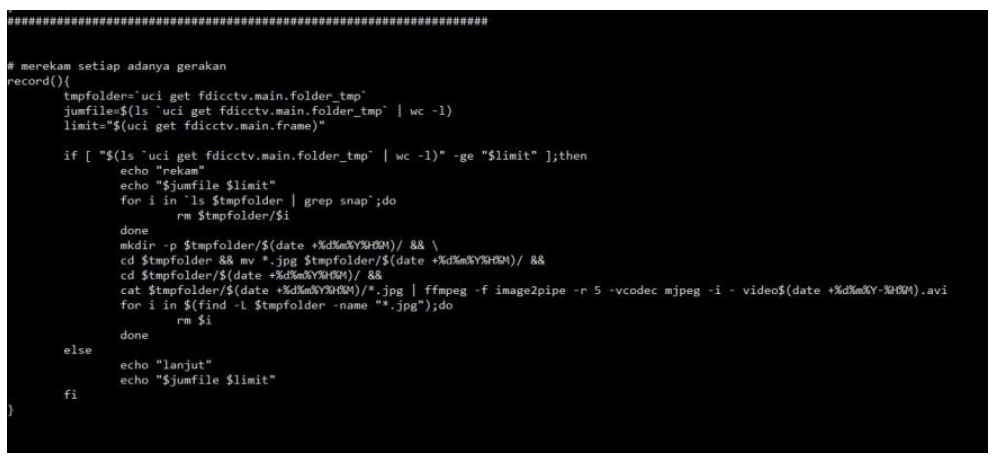

Sumber: Dokumen Pribadi

Gambar 22 Configuration motion

Maka setelah selesai config maka tampilan motion akan berjalan seperti gambar berikut:

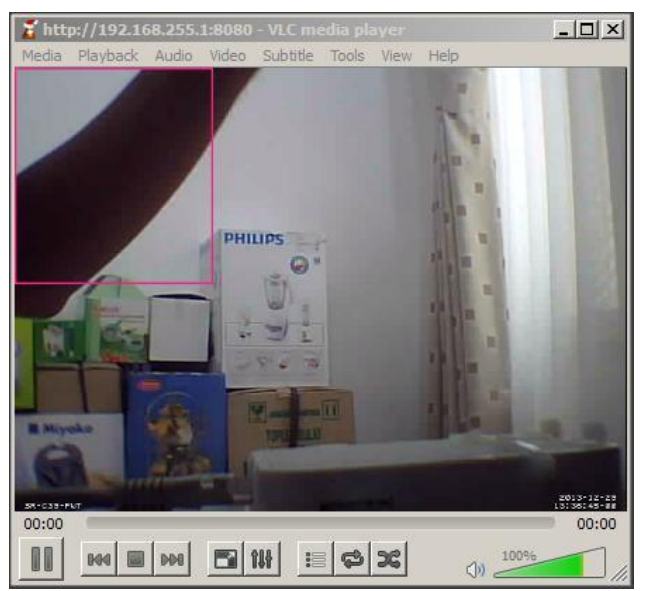

Sumber: Dokumen Pribadi

Gambar 23 Tampilan motion dengan VLC Player

Pada kode pemograman ini dimaksudkan untuk memberikan fungsi perintah pada motion apabila ketika terdeteksi gerakan maka secara otomatis motionakan merekam setiap gerakan yang tertangkap oleh kamera.

\section{Konfigurasi Timmer}

Konfigurasi timmer digunakan sebagai modul penjadwalan pada CCTV openwrt agar dapat diatur penggunaan motion, alarem dan notifikasi email pada jam yang akan di tentukan agar dapat dimaksimalkan penggunaan nya. Berikut kode pemograman pada timmer: 


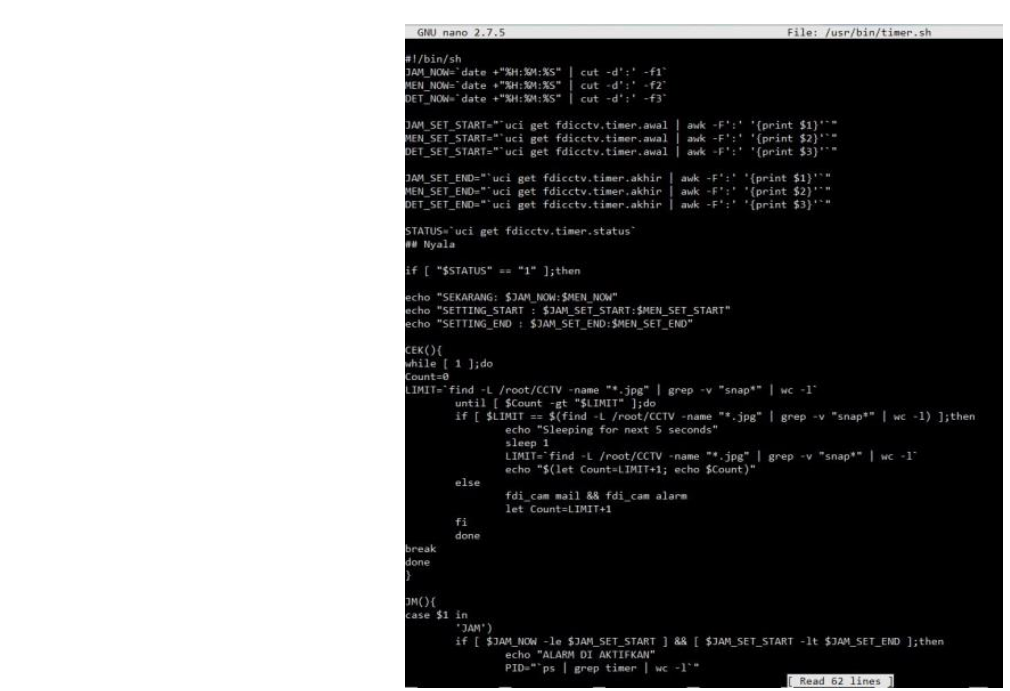

Sumber: Dokumen Pribadi

Gambar 24 Program timmer.sh

Pada pemograman disini terlihat perintah seperti pada gambar yang bertuliskan:

Echo "SEKARANG: \$JAM_NEW:\$MEN_NEW"

Echo "SETTING_START : \$JAM_SET_START:\$MEN_SET_START"

Echo “SETTING_END : \$JAM_SET_END:\$MEN_SET_END”

Codeing ini sebagai perintah yang digunakan untuk mengatur waktu yang digunakan untuk penjadwalan motion, alarem dan notifikasi email.

\section{Install dan konfigurasi mail server}

Untuk mengintal mail server pada openwrt maka dapat digunakan perintah berikut pada terminal:

Step 1.\#opkg install msmtp

Step 2.edit file /etc/msmtprc

Step 3. //contoh pengaturan untuk akun gmail account default hostsmtp.gmail.com port 587 auth on user username@gmail.com password password_email auto_from off from usernamae@gmail.com 
tls on

tls_starttls on

tls_certcheck off

logfile

syslog LOG_MAIL

\section{Installpackage usb soundcard}

Untuk menjalankan alarm maka harus di install terlebih dahulu package usb soundcard agar dapat memutar file alarm yang berformat mp3. Untuk perintah instal nya sebagai berikut:

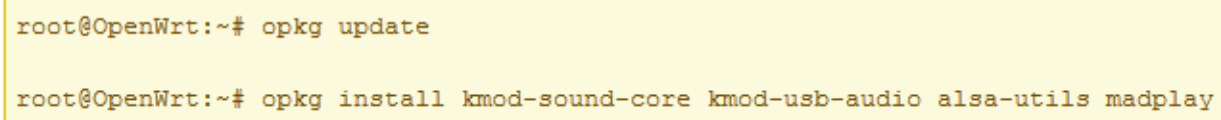

Setelah itu untuk menjalankan nya ketikan perintah seperti berikut:

$$
\text { root@openWrt: \# madplay/root/music/audio.mp3 }
$$

Madplay bukan hanya sebegai pemutar alarem tetapi bisa juga digunakan sebagai pemutar musik dengan format file mp3.

\section{Konfigurasi alarem}

Untuk menjalan kan alarem secara otomatis ketika waktu telah di-setting pada modul penjadwalan maka harus dibuat codeing perintah agar fungsi dari alarem ini bisa langsung bekerja, adapun untuk perintah pada alarem seperti gambar dibawah ini:

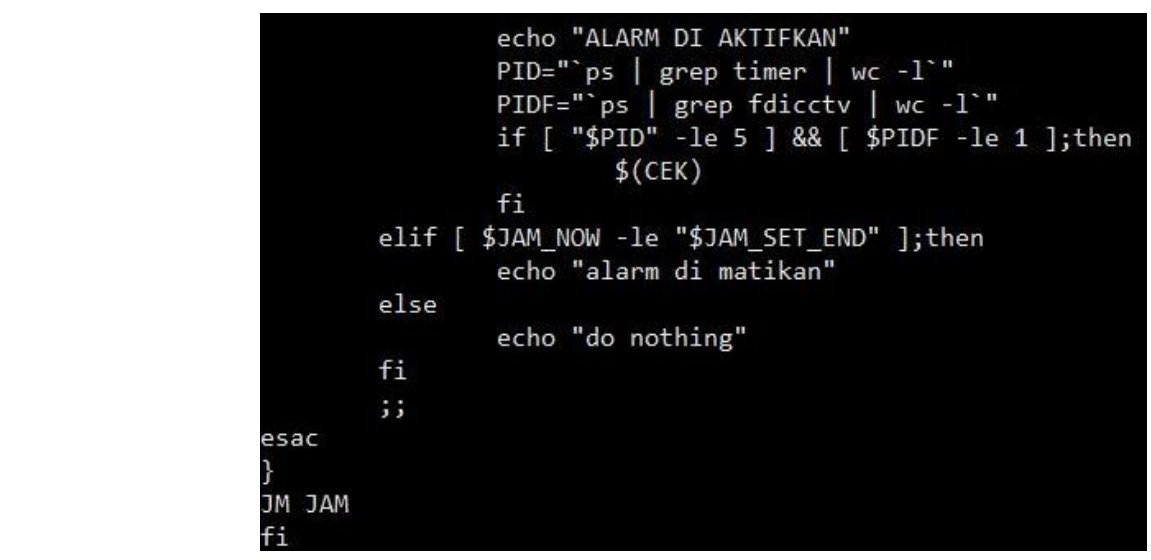

Sumber: Dokumen Pribadi

Gambar 25 Perintah alarem 


\section{Konfigurasi Fungsi CCTV}

Pada konfigurasi CCTV ini di buat beberapa option sebagai perintah untuk semua fungsi pada CCTV yang penulis buat, diantaranya adalah sebagai berikut:

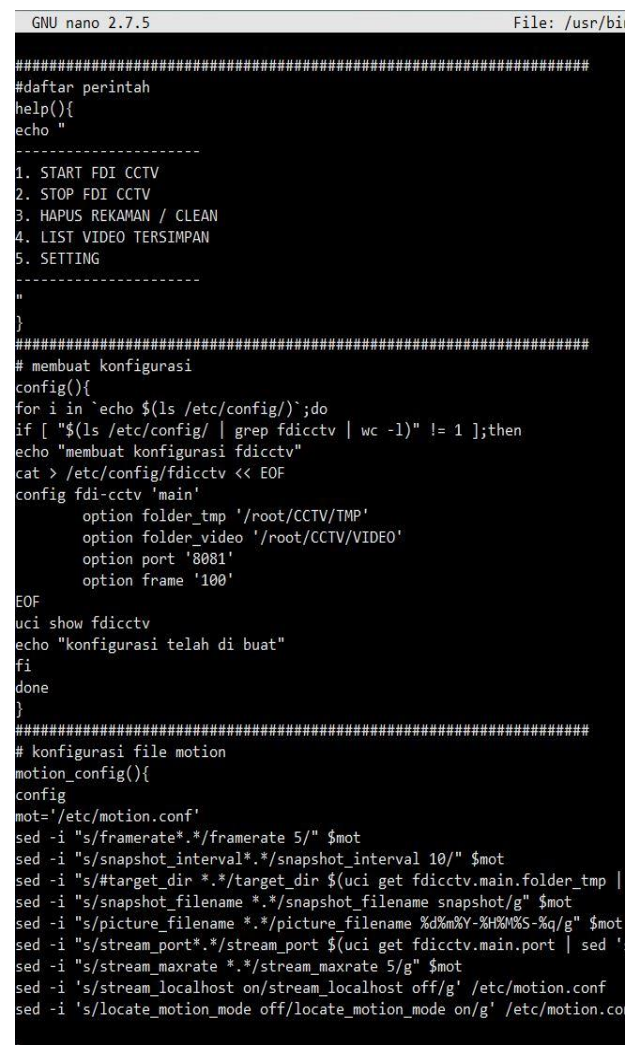

Sumber: Dokumen Pribadi

Gambar 26 Daftar perintah dan fungsi CCTV

Setelah ada daftar perintah dan fungsi pada CCTV maka dibuatlah option seperti dibawah ini:

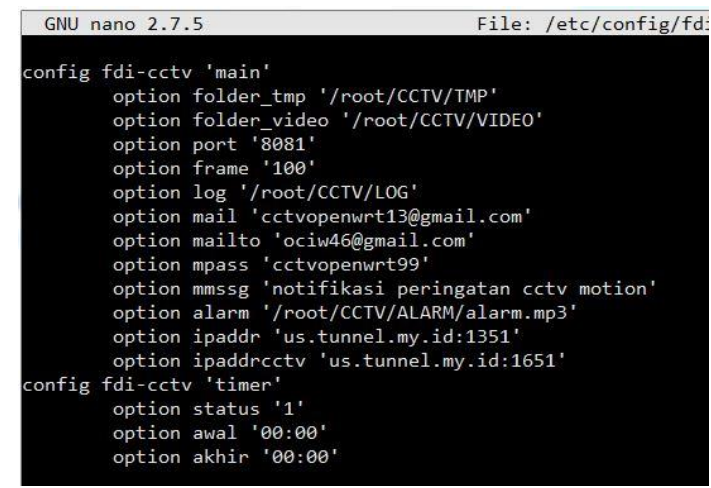

Sumber: Dokumen Pribadi

Gambar 27 Configurasifdi CCTV 


\section{IMPLEMENTASI}

\section{Pengujian Sistem}

\section{Pengujian Sistem Awal}

Pada pengujian awal yang dilakukan yaitu pada CCTV yang tidak dapat mendeteksi gerakan dan tidak dapat memberikan notifikasi mencoba berjalan saat tidak ada aktifitas perkantoran. Hasil yang diperoleh yaitu:

1. Masih sering ada pihak dari luar kantor yang masuk ke area perkantoran tanpa diketahui oleh pihak keamanan kantor.

2. Pencurian diketahui ketika ada laporan dari pihak pekerja dan baru diketahui kapan kejahatan itu terjadi setelah memutar ulang video rekaman.

\section{Pengujian Sistem Akhir}

Pada pengujian sistem akhir CCTV akan terpasang sistem deteksi gerakan dan email notifikasi. Sistem CCTV dengan deteksi gerakan dan notifikasi email, akan dicoba dengan percobaan dijalankan ketika tidak ada aktifitas perkantoran dan sistem ini akan mendeteksi gerakan lalu mengirimkan notifikasi email kepada pengguna.

\section{Monitoring Secara Online}

Pada CCTV yang telah terpasang sistem deteksi gerakan dan notifikasi email akan mencoba me-monitoring dengan web browser dan smartphone android dari hasil yang terjadi pada CCTV yang di-monitoring dari tempat yang berbeda adalah seperti berikut:

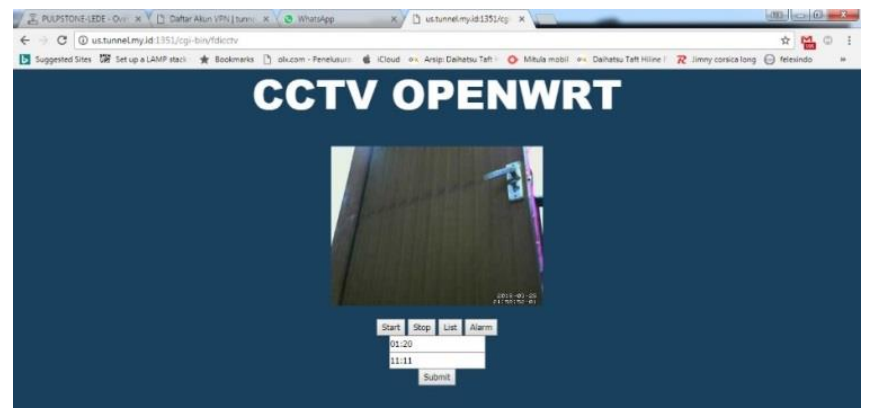

Sumber: Dokumen Pribadi

Gambar 28 Monitoring dengan web browser 


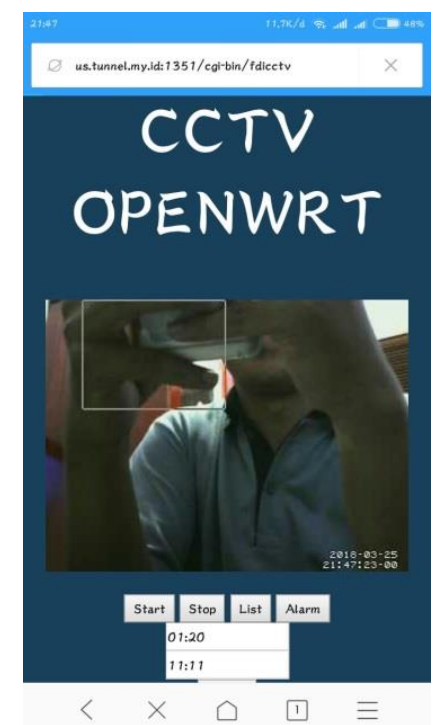

Sumber: Dokumen Pribadi

Gambar 29 Tampilan Monitoring Dengan Smartphone

Gambar tersebut menunjukan hasil tampilan gambar saat sistem dimonitoring melalui web browser yang ada pada leptop atau computer dan melalui Smartphone.

\section{Mengatur Penjadwalan Sistem}

Pada sistem penjadwalan sistem CCTV mencoba di jalankan dengan mengatur waktu yang akan di tentukan pada jam-jam sering terjadi tindak pencurian.

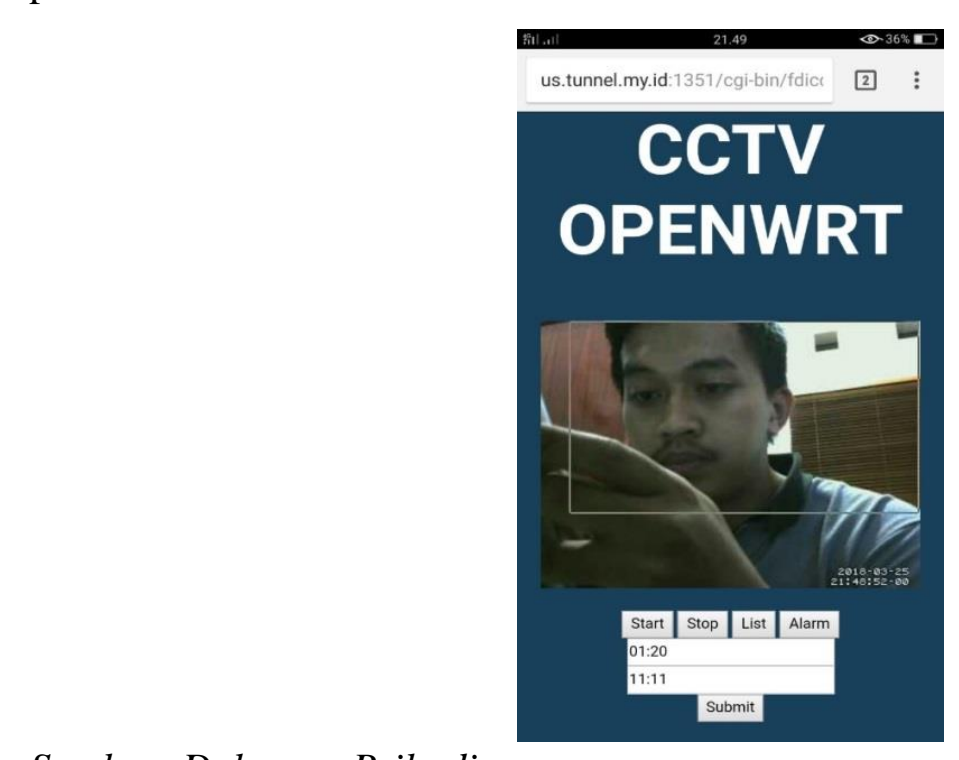

Sumber: Dokumen Pribadi

Gambar 30 Setting Jam Alarem 
Gambar di atas menunjukan waktu yang telah di setting pada jam tersebut agar sistem CCTV dapat memberikan notifikasi kepada pengguna.

\section{Alarem Notifikasi}

Setelah penjadwalan di-setting pada jam yang telah di tentukan maka CCTV akan berjalan dan mendeteksi gerakan setelah gerakan terdeteksi pada sistem CCTV ini maka alarem akan berbunyi dan mengirimkan email kepada pengguna.

\section{Email Notifikasi}

Setelah alarem berbunyi maka email notifikasi pun akan berjalan bersamaan dengan alarem untuk mengirimkan email yang berisikan snapshot/gambar yang terdeteksi oleh CCTV dan mengirimkan nya kepada pengguna dengan melalui email yang telah penulis buat khusus untuk CCTV sebagai pengirim dan memasukan email pengguna sebagai penerima notifikasi gerakan, untuk dapat segera dilakukan pengecekan pada titik dimana sistem CCTV yang penulis buat ditempatkan.

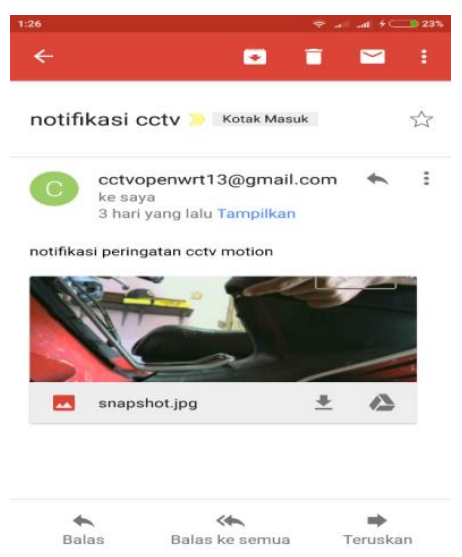

Sumber: Dokumen Pribadi

\section{Analisis}

Gambar 31 Screenshot Notifikasi Email

Dari hasil yang didapat pada pengujian sistem CCTV bawa CCTV openwrt dapat diakses secara online dari manapun selama perangkat terhubung dengan internet. CCTV analog yang hanya bisa di-monitoring secara lokal tidak dapat mendeteksi gerakan yang tertangkap oleh kamera dan tidak bisa memberitahu kondisi sekitar jika tidak terus dipantau didepan layan monitor.

Berdasarkan percobaan sistem yang telah memiliki pendeteksi gerakan dapat langsung mendeteksi setiap gerakan yang muncul pada daerah jangkauan kamera, sehingga sistem dapat langsung memberikan peringatan berupa alaram dan email 
notifikasi kepada pengguna ketika ada seseorang yang ingin memasuki area perkantoran tanpa sepengetahuan pihak keamanan yang ada.

Tabel 1Hasil Pengujian Sistem

\begin{tabular}{|c|c|c|}
\hline \multirow{2}{*}{ No. } & \multirow{2}{*}{ Jenis Gerakan } & Mendeteksi \\
\hline & & Tidak \\
\hline 1 & Manusia/Hewan & $\checkmark$ \\
\hline \multirow{2}{*}{2} & Benda & 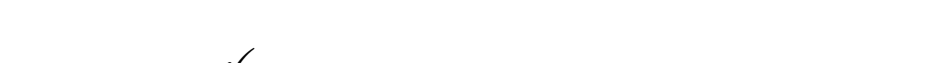 \\
\hline & Mati/Kendaraan & \\
\hline \multicolumn{2}{|c|}{ Kelebihan } & $\begin{array}{l}\text { Mendeteksi semua gerakan yang tertangkap pada } \\
\text { jangkauan kamera }\end{array}$ \\
\hline \multicolumn{2}{|c|}{ Kekurangan } & Setiap jenis gerakan tidak dapat dibedakan. \\
\hline
\end{tabular}

Sumber: Dokumen Pribadi

Motion tidak dapat membedakan jenis gerakan karena hanya dapat mendeteksi gerakan dengan cara membedakan pixel dan email yang digunakan hanya dapat dikirimkan ke satu akun email saja.

\section{KESIMPULAN}

Berdasarkan hasil penelitian yang telah dilakukan, ada beberapa hal yang dapat disimpulkan, yaitu:

1. Sistem telah mampu mendeteksi gerakan pada ruangan dengan menggunakan webcam dan dapat di akses dari mana saja ditempat yang berbeda selama perangkat terhubung dengan internet.

2. Sistem telah mempu meberikan notifikasi atau peringatan melalui email dan alaram secara realtime.

\section{SARAN}

Menyadari bahwa di dalam penelitian ini banyak sekali kelemahan dan kekurangan, oleh sebab itu ada beberapa hal yang dapat dilakukan untuk memperbaiki kekurangan dan kelemahan, yaitu:

1. Penggunaan internet dengan kecepatan upload yang tinggi agar sistem monitoring ini lancardiakses. 
2. Pada sistem ini masih sering terjadi false alarm sehingga perlu membuat sebuah aplikasi pendeteksi gerak sendiri yang dapat berjalan dibawah sistem operasilinux.

3. Penggunaan kamera webcam dengan resolusi yang tinggi agar gambar yang ditangkap lebihjelas.

4. Perlunya penggunaan media penyimpanan yang memiliki kapasitas yang besar agar dapat menampung lebih banyak video dengan resolusi yang tinggi.

\section{DAFTAR PUSTAKA}

Adriansyah. dkk. (2014). Rancangbangun dan Analisa Cctv Online Berbasis Raspberry Pi. SINERGI. Vol.18 No.(2). 105-110

Andi. (2012). How To Send Mail with Attachment in PHP.[Online]. Tersedia: http://xahlee.info/php/send_html_mail.html[5 Januari 2018].

Aji dan Supriyanto, (2009) Pembuatan Model Live Streaming CCTV berbasis Web dengan Open Source, Jurnal DINAMIK. Vol XIV No.(2) 1-8

Atmoko E H (2012). Membuat Sendiri CCTV Berkelas Enterprise Dengan Biaya Murah. Jakarta: Andi Publisher

Cahyadi B (2014). Home Security: Membuat Webcam Sebagai CCTV Melalui Smartphone Android. Jakarta: Andi Publisher

Hari, dkk. (2012) Membuat sendiri CCTV Berkelas Enterprise dengan Biaya Murah, Jakarta: Salemba.

Lavrsen, K. (2006). Legacy Motion Guidefor Motion versions 3.1.18-3.1.20. [Online].

http://www.lavrsen.dk/foswiki/bin/view/Motion/MotionGuide 3x1x20 $\underline{10}$ [10 Februari 2018].

Nixcraft. (2006). How To : Add Jobs To cron Under Linux or UNIX [Online] Tersedia: http://www.cyberciti.biz/faq/how-do-i add-jobs-to-cron-underlinux-or- unix oses/ [1 maret 2018].

Ni'am, Muhammad. (2012). Kelebihan bahasa-bahasa Pemrograman. [online]. Tersedia:http://el-muben.blogspot.com/2012/02/kelebihan-bahasabahasapemrograman6630.html [25 Februari2018]

Purbo, dkk. (2011) Jaringan Wireless di Dunia Berkembang. Panduan Praktis Perencanaan dan Pembangunan Infrastruktur Komunikasi yang Rendah. Yogyakarta : Elex Media Komputindo. 
Romi, Agustian. (2011). Perancangan Sistem Keamanan Rumah Menggunakan Perangkat Nirkabel berbasis Openwrt. Surabaya: Universitas Wijaya Kusuma.

Saputra. dkk. (2017). Pelacakan Dan Deteksi Wajah Menggunakan Video Langsung Pada Webcam. Jurnal Telematika.. Vol.10 No.(1). 50-59

Shadiq. dkk. (2014). Perancangan Kamera Pemantau Nirkabel Menggunakan Raspberry Pi Model B. TRANSIENT. Vol.3 No.(4). 1-6

Wahana. (2005). Pengembangan Aplikasi Sistem Informasi Akademika Berbasis SMS dengan JAVA. Jakarta: Salemba.

Wardana. (2010). Menjadi Master PHP dengan Framework Codeigniter. Yogyakarta : Elex Media Komputindo.

Wirawan, A. (2012). Prototype System Sekuriti Ruangan Berlapis Berbasis Mikrokontroller avr-atmegal6 Dan Jaringan Syaraf Tiruan. Yogyakarta: UIN Sunan Kalijaga.

Wibowo dan Agung, (2004) Multimedia dan Streaming, Jakarta: PT. Elex Media Komputindo.

Yuliardi dan Rofiq.(2002). BASH Scripting Untuk Administrasi Sistem Linux. Jakarta: ElexMedia Komputindo. 